\title{
The Development of Sprayed Concrete and Construction Technology Research
}

\author{
Ruyi WANG ${ }^{1,2}$, Ziyi HOU $^{2}$, Jiliang WANG ${ }^{1}$ \\ (1.Research Institute of Highway, Ministry of Transport, Beijing \\ 100088,China; 2.School of Civil Engineering, Hebei University of Technology, Tianjin 300401,China) \\ (1.1099882336@qq.com 2.2772001123@qq.com 3.178089788@qq.com )
}

Keywords: Sprayed concrete; Current situation of the development; Performance characteristics; construction technology

Abstract. Shotcrete is the best method to deal with the slope repair, surrounding rock bolting and other projects. This paper first summarizes current situation of the development of the sprayed concrete at home and abroad, and points out its characteristics; Secondly, discussing the supporting principle and the selection of raw materials, with the emphasis on accelerating agent in the research and application of sprayed concrete construction; Finally, introducing sprayed concrete construction technology which mainly narrative the wet spraying technology, and pointing out the problems existing in the construction of the sprayed concrete .

\section{Introduction}

In recent years, with the rapid development of transportation enterprise, debris flow, landslide and the frequency of disasters such as collapse are also rising year by year, so the problem of the pre-disaster prevention and post-disaster rapid repair gets attention of more and more experts and scholars. Using shotcrete technology road fast repair reinforcement, treatment, tunnel surrounding rock support, slope reinforcement is undoubtedly the most economical, reasonable and efficient method to solve the problem. Shotcrete refers to the use of the power of compressed air through a spray concrete mixing material into the rock and buildings on the surface which will tightly stick together and then condens a concrete. The initial prototype of the shotcrete is the development of the sprayed cement mortar. Generally sprayed concrete doesn't need a template support, so that it can reach the purpose of reducing cost and save the investment. What the characteristics of the shotcrete is that the Strength increasing fast, the compactness is good, the operation of the construction is simple and the strong adaptability, etc. Because of these characteristics of sprayed concrete which makes it widely used in hydraulic tunnels, traffic tunnel and shaft, mining and other underground buildings and support as well as the slope anchor spray reinforcement of concrete; [1-5] And tank, large pipes, the concrete construction of underground water impermeability and the operating and repairing technology of various kinds of concrete structures [6-8].

\section{The development situation at home and abroad}

\subsection{Foreign development situation}

It Ohas a history nearly a century with sprayed concrete technology research and development. Abroad began the exploration of the shotcrete prototype from the early twentieth century. The United States first to use the jet cement mortar in the civil engineering and the mining engineering in 1914. Austria used shotcrete support in tunnels in the cave of the construction of card drugs hydropower station between 1948 and 1953, and obtained good construction effect. Later, in Switzerland, France, Germany, Sweden, the United States, Britain, Canada, Japan and other countries, one after another in including civil building engineering, tunnel engineering projects such as adoption and development of the technology of sprayed concrete. The sprayed concrete technology is also in constant development and mature gradually in the practice and exploration in the study of application[9]. 


\subsection{The current situation of the development of domestic}

Sprayed concrete technology starts relatively late in China, We promote new began to adopt the method in railway tunnel construction since the late $1960 \mathrm{~s}$. But for a long time for the research and application of sprayed concrete technology is very seriously in China. We developed the tidal type concrete jet independently, which laid the foundation of the development of the spraying technology during the period of "seventh". In the early eighty s, along with the increase of the tunnel and underground engineering in our country, wet spraying concrete in our country gradually developed.

Due to the huge volume wet-spray machine and the supporting system, which coordinates with the current excavation supporting sex difference, Then the basic material and additive cannot meet the requirements of pumping process well, so wet jet technology has not yet fully applied in our country. If the sprayed concrete technology want to develop well, it also needs to the development of its raw materials performance, test methods, construction technology and so on carries on the detailed research[10].

\section{The characteristics of the sprayed concrete}

\subsection{Early strength and pounding}

Accelerator, which is the most important additive of sprayed concrete, has an effect on the hydration and hardening of the cement, the formation of the strength which is sufficient, in a short time, so as to ensure the requirement of the construction which is special [11].In addition, sprayed concrete can be jetted from the spray nozzle to the surface of rock, in a high speed $(40 \sim 120 \mathrm{~m} / \mathrm{s})$, thus the concrete which is jetted onto wall first will be impacted strongly and pressure by the spray concrete which is jetted onto wall after, so that the concrete structure is compacted and has high strength. The construction does not need manual stamping.

\subsection{Cohesiveness and flexibility}

Because of the sprayed concrete jetted on the wall in high speed, so that the cohesive force with the surrounding rock is great, such that it will make it easy to closed surrounding rock timely and prevent the weathering and strength decrease of surrounding rock. The layer of the sprayed concrete is thinner, thus it has a certain flexibility, so that it can be coordinated with the surrounding rock deformation, finally achieving the goal of making pressure and pressure relief.

\subsection{Convenient construction, low cost, wide range}

In the process of supporting, the sprayed concrete makes concrete construction such as transportation, water, vibrating process into a working line, thus it can eliminate the program, which include multifarious dismantle process, so that it can make the construction craft simple; Shotcrete is also available long-distance conveying pipe construction, the construction is convenient and fast. Source of raw materials can be widely used in the construction process and the construction cost is low. Moreover sprayed concrete can not only as a permanent support, but also can be used in tunneling working face temporary support.

\section{The support mechanism of shotcrete}

\subsection{Support function}

In the process of construction, sprayed concrete has good physical and mechanical performance, it has the certain compressive strength (up to $25 \mathrm{mpa}$ ) and bearing capacity, thus it can play the role of supporting pressure. For adding the sprayed concrete hardener, which makes the concrete setting fast and the working face operation. At the same time it has the effect on supporting of surrounding rock timely. 


\subsection{Filling effect}

As a result of the concrete jet velocity is higher so that it can be fully filling the surrounding rock fracture, joint and recesses of borehole, thus the strength of the surrounding rock can be enhanced greatly.

\subsection{Isolation effect}

Closed to the surface of the surrounding rock, Shotcrete layer can be completely isolated from moisture and air which contacts with wall rocks, thus it can prevent the deliquescence, weathering effectively which causes peeling off and destruction of the surrounding rock.

\subsection{Conversion action}

In the process of sprayed concrete construction, concrete layer is formed on high speed jet to the face of tock, it has the very high cohesive force, which makes concrete and rock together. It can transmit all kinds of stress on the combination and make the concrete layer and the surrounding rock formed a joint bearing mechanical system, with the effect of rock load into the role of the bearing structure.

\section{The choice of raw materials of sprayed concrete}

\subsection{Cement}

Varieties of cement and the strength grade should meet the requirements of the engineering practice, the choice of when join the accelerator, the compatibility of cement and accelerating agents should also be considered.

The cement of sprayed concrete can be divided into three categories: [12]

(1)The first kind is a series of silicate cement, such as Portland cement and ordinary Portland cement, which the strength grade not less than $32.5 \mathrm{Mpa}$. If the sprayed concrete apply this kind of cement, it will need the coagulant function of the accelerator. The dosage and varieties of the accelerator should be determined by test in advance.

(2)The second type is a special jet cement, this kind of cement composition is mainly refers to the cement varieties, Which contains fluoride calcium aluminate by itself. It has a rapid setting properties (generally it just need $10 \sim 20$ min to final set, the strength can reach more than $10 \mathrm{Mpa}$ within $6 \mathrm{~h}$ and the strength can reach more than $30 \mathrm{Mpa}$ within $1 \mathrm{~d}$.) In addition this kind of cement mixed with a certain amount of tricalcium silicate, so the late strength is high.

(3)The third type of cement is mainly some cement that used on special occasions. It mainly has specific performance. The application of the Shotcrete construction is the cement which is generally not adding accelerator, especially the high alumina cement, when adding accelerator will reduce the strength of concrete even split of serious consequences, because of the drying in carbonate of the accelerator will react with the hydration products of the high alumina cement.

\subsection{Aggregate}

(1)Coarse aggregate, pebbles or gravel, but with pebbles as well. Not only the erosion of the pebble to the equipment is lesser, but also it hard to cause pipeline jam like rock which with the needle fake content. Although the current domestic production of jet function can use maximum aggregate diameter is $25 \mathrm{~mm}$, but in order to reduce springback, the largest aggregate diameter should not be greater than $20 \mathrm{~mm}$. When the sprayed concrete should be mixed with hardener, it shall not be made coarse aggregate contains active silica stone, lest the alkali aggregate reaction which will make the sprayed concrete cracking destruction.

(2)Fine aggregate can be used without weathering river sand or mountain sand, fineness modulus should be between $2.7 \sim 3.7$, which is less than $0.075 \mathrm{~mm}$ diameter of fine sand should be less than twenty percent. Move fineness will not only affect the injection performance, but also affects on the surface of the water slurry and aggregate bond[13]. 
In addition, the ratio of coarse aggregate and fine aggregate has an important effect on the pumpability of sprayed concrete, the liquid through a pipeline, due to adhesion and the final product of the spray density and economy, thus enough concern must be paid.

\subsection{Admixtures}

\section{(1)Accelerator[14]}

The main purpose of the accelerator add to the sprayed concrete is to make its quick-setting rapid hardening, reducing the loss of the springback, prevent the loss caused by gravity and improve its resistance to moisture, at the same time it also can appropriately increase the thickness of a jet and shorten the time interval between the spray layer. The technical requirements of the standard JC $477-2005<<$ the shotcrete with accelerator $>>$ of China's building materials industry is shown in table 1: [15]

Table 1 The performance requirements of the mixing accelerator net pulp and hardened mortar

\begin{tabular}{|c|c|c|c|c|}
\hline \multirow[b]{2}{*}{ product level } & \multicolumn{2}{|c|}{ net pulp } & \multicolumn{2}{|c|}{ mortar } \\
\hline & $\begin{array}{c}\text { initial setting } \\
\text { time } / \mathrm{min}\end{array}$ & $\begin{array}{l}\text { final setting } \\
\text { time } / \mathrm{min}\end{array}$ & $\begin{array}{l}\text { 1d compressive } \\
\text { strength/Mpa }\end{array}$ & $\begin{array}{l}\text { 28d compressive } \\
\text { strength/Mpa }\end{array}$ \\
\hline grade a & $\leq 3$ & $\leq 8$ & $\geq 7.0$ & $\geq 75$ \\
\hline $\begin{array}{l}\text { nonconforming } \\
\text { product }\end{array}$ & $\leq 5$ & $\leq 12$ & $\geq 6.0$ & $\geq 70$ \\
\hline
\end{tabular}

Accelerator research in China started relatively late, the early development study of accelerator is mainly powder (such as red star type I accelerator: the accelerator was developed by the Chinese academy of sciences institute of engineering mechanics in 1996. It consists of, alumina clinker, soda ash and lime mixture. Under standard conditions, when the dosage of $2 \%$, net cement slurry final setting time is $6 \mathrm{~min}, 1$ day compressive strength value is not mixed three times; when the dosage of $2.5 \%$, it can make the initial setting cement slurry net less $1.5 \mathrm{~min}$, final set within 7.5 minutes, 1 day, 3 days and 28 days compressive strength value is respectively 8.4, 22.0 and $22.0 \mathrm{MPa}$ )/Alkaline accelerating agent (such as the type 711 accelerator: 711 type accelerator was developed by Shanghai building scientific research institute and Shanghai silicate products factory in 1971 .It is made of alumina, soda ash, lime mixed burning after the mature makings add anhydrite fine grinding, its main components in sodium aluminate, dicalcium silicate and sodium iron. When the dosage of 3.5\%, net cement slurry in the final set within $3 \mathrm{~min}, 1$ and 28 days compressive strength values are 8.1 and 43.2 $\mathrm{MPa}$.) what the disadvantages is high alkali content and late strength loss[16].

With the widely application of sprayed concrete technology in our country in the $1990 \mathrm{~s}$, our country begans to get the initial research and development of the low alkali liquid, liquid alkali-free accelerating agent. Such as zhi-hua pan by Nanjing university of technology developed the NSA liquid alkali-free accelerating agent. This kind of accelerator in silicate cement has good coagulation effect, the appropriate mix content of $8 \% \sim 9 \%$, the corresponding initial setting time is less than 5 min, final setting time is less than $10 \mathrm{~min}$, besides it also has different degrees of promoting function to the early strength of cement and has no adverse effect on the strength of $28 \mathrm{~d}$, retention rate of no less than $100 \%[17]$.

And as by Beijing university of technology and Beijing Newport cement manufacturing joint developed the SL-1 and the SL-2 two low alkali liquid accelerators. These physical, chemical properties, strength and setting time and so on are very well in the laboratory[18-19].

Even so, China's development of liquid alkali-free accelerating agent is still in the primary stage, its mainly exist the following problems: (1) The adaptability between no (low) alkali liquid accelerator and different strength grade or different kinds of cements; (2) The instability of coagulation time; (3) There is a great influence on the strength of concrete; (4) The content is not easy to control, product yield is low, the price is expensive; (5) The Shotcrete construction and quality control become more and more harder with adding the no (low) alkali liquid accelerator.

(2)Water reducing agent 
Water reducing agent is added to sprayed concrete not only can improve the strength and durability of concrete, but also can reduce the springback amount of construction effectively. Trying to choose water reducing agent to the type of gas and the retarding water reducing agent, There is no special requirements for water reducing rate.

(3)Early strength agent

When using series of silicate cement . In order to improve the early strength of sprayed concrete, often require adding a certain amount of early strength agent. If it is reinforced concrete should be chosen for reinforced non-corrosive effect of early strength agent. A high early strength, high alumina cement itself without adding early strength agent.

(4)Waterproofing agent

It should be mixed with a certain amount of waterproofing agent in concrete when sprayed concrete need have higher permeability resistance, such as waterproofing agent UEA, it can be used triethanolamine and water reducing agent in order to achieve the effect of waterproof, at the same time.

\section{The discussion for sprayed concrete construction technology}

Traditional shotcrete construction processes are mainly consist of dry spray type sprayed concrete construction and wet spray type sprayed concrete construction. In recent years, developing lots of new types of sprayed concrete construction technology, which are on the basis of above construction methods and through continuous engineering test research, such as cement coated sand method and fiber shotcrete method, etc. The 21 st century, our country's sprayed concrete technology is the development by leaps and bounds, basically reached the international level[12].

\subsection{Dry spray type sprayed concrete}

The mixture of cement, which the water cement ratio is less than 0.25 , sand, gravel mixture and mixing powder accelerating agent according to certain proportion, using dry shotcrete machine, powered by compressed air, through the feeding tube to the nozzle, mixed with a certain amount of pressure water, spraying jet to the surface. If using dedicated combined bolting and shotcrete quick-setting cement, thus it can not add the accelerator. On the other hand, it must be joined the accelerating agents for achieving the purpose of rapid condensation sclerosis.

Its advantages are (1) The construction technological process is simple, convenient, need less construction equipments (only mixer and dry spray machine); (2) The long transmission distance, flexible construction layout, conveying distance of up to $300 \mathrm{~m}$, vertical distance can reach $180 \mathrm{~m}$; (3) As the main additive accelerator can join in advance, mixing evenly[20].

Its disadvantages are (1) The face amount of dust and the springback amount is larger, with bad work environment, physical harm to construction personnel, uneven spraying material; (2) The actual cement water quality difficult to control, the serious influence at the concrete quality. (3) The production efficiency is low, besides it is not conducive to the construction schedule control.

\subsection{Wet spray type sprayed concrete}

Mixing the cement, sand, gravel and water to form a concrete, in certain proportion (water cement ratio is 0.5 or so commonly, slump around $140 \mathrm{~mm}$ ), the mixed concrete is transported to the nozzle through the pipe pressure of the air pump, then blending with liquid accelerator, finally with the help of wind pressure to jet the concrete to the working plane in high-speed. The advantages of the construction technology are (1) The dust of the working face is little;(2) The rate of the rebound of the sprayed is low;(3) The strength of the concrete is high; The disadvantages of the construction technology are (1) To control the construction technology is hard; (2) More strict with aggregate ratio and the admixture; (3) The distance of conveying is shorter (generally no more than $50 \mathrm{~m}$ ).

The features of wet spraying method construction technique are : (1) The water cement ratio can accurately control; (2) Spray mixing concrete mix adequately, the advantage is the fully of hydrated 
cement, and then the higher strength of concrete will get; (3)The accelerator generally can't join in advance, it should be join after the jet; (4) The dust and the springback amount are low and there is a good production environment; (5) The equipment of the wet sprayare more complexed besides it is difficult to join the accelerating agents to the concrete.

\subsection{The method of Cement wrapped sand}

Sand Enveloped With Cement referred to as "the SEC" sprayed concrete, the essence of which is wrapped in Cement Sand injection material and made into slurry, pumping, and then mixed with the dry jet which can transport the dry material, then jet to the surface through the nozzle. The advantages of "the SEC" are: (1) The sprayed concrete and the spray surface bonding performance is good; (2) The dust of the working face is little; (3) The amount of the springback is small; (4) the strength of the concrete is high, the distance of conveying is long.

\subsection{Fiber shotcrete}

Steel Fiber Reinforced Shotcrete or Steel Fiber Reinforced Sprayed Concrete: the mortar or concrete which contains discontinuous distribution of steel fiber reinforced through pneumatic power high speed jet to the spray surface, also known as steel fiber concrete[21].

At present, the steel fiber reinforced concrete has been used as a major concrete material all over the world, its advantages: (1) with higher strength and deformation; (2) there is still a high residual strength after damage so that it can make the sprayed concrete has better toughness, bending, shear and fatigue resistance, and even its flexible far more than the ordinary concrete, the bending strength increased about fifty percent to one hundred percent, the shear strength increases by about thirty percent to fifty percent, and toughness increase several times. Its disadvantages: (1) the high cost; (2) mixing ingredients easy to cluster so that it is not conducive to control the construction schedule; (3) when jet construction it is very easy to block pipe, and hurt the person by the springback; (4) in addition, the corrosion of steel fiber also makes concrete surface rust spots then affect its beautiful. Fiber shotcrete are generally use of existing shotcrete equipment and construction technology, above the spray dry spray, wet and SEC sprayed concrete, mixing with the right amount of fiber and fiber reinforced shotcrete. At present, people adopt new materials super hybrid fiber instead of steel fiber shotcrete construction performance to study, even lots of physical properties similar with the mixing steel fiber reinforced concrete, what the advantages of it is the injection effect is better, the cost is low, and the economic effect is remarkable, so it has great popularization value[22-24].

\section{Conclusions}

This paper mainly studied the development, characteristics, supporting principle, the selection of raw materials and construction technology of the shotcrete. It is focus on the selection of accelerator, the characteristics of wet type sprayed concrete and technological process. We may draw the following conclusion through the above research:

(1) The application of sprayed concrete is widely throughout the world, especially it is necessary in applying in the engineering such as supporting engineering aspects and tunnel lining, thus it has very big development space and is worthy of further perfecting and research;

(2) Accelerator is an important part of the sprayed concrete, its market development is wide prospect, besides non-alkali liquid accelerator is still an very important accelerator research direction, but there are many problems, such as dosage of its adaptability, stability, impact strength, price and construction quality control;

(3) In numerous of categories of construction of technology sprayed concrete, wet shotcrete technology is still occupy the main position, the optimization of its construction technology is a important direction in the future sprayed concrete research; 
(4) There are a lot of shortcomings of the sprayed concrete construction process, so there need further construction practice and it is very important to develop new technology to suitable for modern concrete construction .

\section{References}

[1] ZHANG Wangling. Technical support by rockbolt and shotcrete in the applied research of the camp of the shadow of coal mine [J]. Intelligence development of science and technology and economy, 2005,1(15): 277-278.

[2] ZHANG Di, LIAO Weidong, LIU Qiang. Sprayed concrete performance and mixture ratio of experimental research [J]. Journal of Wuhan university of technology, 12(12): 53-55.

[3] MASAYASU H. Effects of steel fiber reinforced high-strength shotcrete in asqueezing tunnel [J].Tunnelling and Underground Space Technology,2003(18):197-204.

[4] MALMGREN L,NORDLUND E,BOLUND S. Adhesion strength and shrinkage of shotcrete[J].Tunnelling and Underground Space Technology,2005(20):33-48.

[5] LEUNG CKY, ASCE M,LEEAYF , etal. A new testing configuration for shrinkage cracking of shotcrete and fiber reinforced shotcret [J].Cement and Concrete Research , 2006(36):740-748.

[6] WANG Lan. Composition.Performance. The application of cement concrete[M]. Bei Jing: China building industry press, 2005:836-837.

[7] TRANVNG, BERNARDES, BEASLEYAJ. Constitutive modeling of fiber reinforced shotcrete panels [J].Journal of Engineering Mechanics,2005,131(5):512-611.

[8] CHENSH, FUCH, SHAHROURI. Finite element analysis of jointed rock masses reinforced by fully-grouted bolts and shotcrete lining $[\mathrm{J}]$. Intertional Journal of

Rock Mining sciences,2009(46):19-30.

[9] MA Zhongcheng, WANG Lan, MA Jingyu. Sprayed concrete technology and the development of the accelerator[J]. Concrete , 2011, 39(12):126-128.

[10] ZHANG Xiang-dong, ZHANG Shu-guang, LI Yong-jing. The development and application of sprayed concrete technology[J]. Coal science and technology , 2001,10(1):19-21.

[11] LEEST.KIM DG. JUNGHS. Sulfate attack of cement matrix containing inorganic alkali-freeaccelerator[J].KSCEJournalofCivilEngingeering,2009,13(1):49-54.

[12] FAN Wenxi, GENG Yungui, HAN Jianjun. High performance sprayed concrete parameters optimization research[J]. Journal of coal, 1999, 24(5): 481-484.

[13] FAN Wenxi, GENG Yungui, WANG Fu-long. High-performance sprayed concrete technology research[J]. Build well technology, 1999, 20(3):24-26.

[14] HE Tingshu. Concrete additive[M].XI an: Shanxi science and technology press, 2004.

[15] JC 477-2005, Sprayed concrete with hardener[S].

[16] QING Yizhong. Research Achievements and Outlook of Concrete Accelerators [ J ]. Yunnan Metallurgy, 1998, 27 ( 1 ): 16 - 20. (in Chinese)

[17] PAN Zhihua, CHENG Jiankun . The Status and Research Development of Cement Accelerators[J]. Mine Construction Technology, 2005, 26( 2) : 22 - 27.

[18] LI Qiong. Study on Liquid Low-alkali Shotcrete[D]. Beijing: Beijing University of Technology, 2003.

[19] Wang Ziming, LI Qiong, CHENG Yansong, etc . Study on SL Liquid Low-alkali Shotcrete[J]. China Cement, 2003, ( 6) : 30 - 32. 
[20] WANG Hongxi, CHEN Youzhi, DING Qingjun. The status quo and development of sprayed concrete[J]. Geotechnical engineering technology, 2004, 18(1): 51-54.

[22] MALMBERG B. Quality and quantity variations of wet and dry mix shotcrete -experiences from grodinge railway track project. Shotcrete for underground support VII[M]. Telfs, 1998:251-258.

[23] BANTHIAN, TROTTIER J. Steel-fiber-reinforced wet-mix shotcrete: comparisons with cast concrete [J].Journal of Material in Civil Engineering, 1994,6(3): 430-437.

[24] AUSTIN S, ROBINS P. The rheolorgical performance of wet-process sprayed mortars [J]. Magzine of concrete Rexearch, 1999, 51(5): 341-352. 